УДК 332.1

DOI 10.18101/2304-4446-2020-3-12-21

\title{
ИСПОЛЬЗОВАНИЕ DPSIR \\ ДЛЯ СРАВНЕНИЯ МЕТОДОЛОГИЧЕСКИХ ПОДХОДОВ К ИЗМЕРЕНИЮ ЭКОЛОГО-ЭКОНОМИЧЕСКОЙ ИНФОРМАЦИИ
}

(С) Бардаханова Таисия Борисовна

доктор экономических наук, ведущий научный сотрудник

E-mail: tbard@binm.ru

\author{
() Мункуева Виктория Дабаевна \\ ведущий инженер \\ E-mail: munvic@mail.ru
}

Байкальский институт природопользования СО РАН

Россия, 670047, г. Улан-Удэ, ул. Сахьяновой, 8

Эколого-экономическая информация является важным инструментом описания причинно-следственных взаимосвязей между экологическими, экономическими, социальными, технологическими средами. Авторы предлагают использовать DPSIR как концептуальную модель для структурирования различных подходов и показателей с единой точки зрения. В статье проведен сравнительный анализ подходов к оценке экологической устойчивости с применением DPSIR: оценка жизненного цикла (LCA), метод планетарных границ (PB) и цели устойчивого развития (SDGs). Использование DPSIR в анализе эколого-экономических взаимодействий позволяет выявить узкие места и оценить правильность установления причинно-следственных цепочек, способствует выбору правильных наборов индикаторов для конкретной цели. Разработанный авторами на основе 16 показателей составной индекс по оценке прогресса в развитии зеленой экономики практически отражает все категории DPSIR и позволяет отразить разные аспекты эколого-экономического развития на региональном и локальном уровне.

Ключевые слова: эколого-экономическая информация; индикаторы; DPSIR; зеленая экономика; составной индекс.

\section{Для цитирования}

Бардаханова Т. Б., Мункуева В. Д. Использование DPSIR для сравнения методологических подходов к измерению эколого-экономической информации // Вестник Бурятского государственного университета. Экономика и менеджмент. 2020. № 3. С. 12-21.

\section{1. Введение}

За прошедшие десятилетия измерение эколого-экономической информации набирает обороты как важный инструмент мониторинга и оценки экологических ресурсов и их взаимосвязи с экономическими показателями. Примерами являются многочисленные публикации ученых, доклады о состоянии окружающей среды, отчеты о прогрессе в развитии зеленой экономики и пр., издаваемые ежегодно национальными и международными природоохранными агентствами ${ }^{1}$. Эколо-

${ }^{1}$ UNEP. Using indicators for Green Economy Policymaking. Nairobi, Kenya: UNEP, 2014; Hsu A. et al. Environmental Performance Index. New Haven, CT: Yale University, 2016. URL: www.epi.yale.edu; OECD (2019), Biodiversity: Finance and the Economic and Business Case 
T. Б. Бардаханова, В. Д. Мункуева. Использование DPSIR для сравнения методологических подходов к измерению эколого-экономической информации

го-экономическая информация является важным инструментом усиления процессов международной интеграции, реализации международных инвестиционных проектов, создания совместных предприятий, повышения устойчивости национальных экономик. Тем не менее одной из основных проблем для ведения эффективной экологически ориентированной политики на региональном, национальном и международном уровнях является недостаточность информационного обеспечения процессов принятия долгосрочных решений, а также наличие пробелов в информации, вызванных несовершенством знаний, несогласованностью данных или ненадлежащей работой механизмов, обеспечивающих потоки данных.

Необходимым условием для измерения и оценки эколого-экономической информации является определение адекватных наборов показателей и определение функциональной схемы для описания причинно-следственных взаимосвязей между экологическими, экономическими, социальными, технологическими средами. Как отмечается в статье [1], индикаторы являются простым способом ответить на вопрос: «Как я могу объективно знать, становится ли все лучше или хуже?». С помощью различных индикаторов и соответствующих методов можно оценить прогресс в достижении устойчивости деятельности или реализации принципов зеленой экономики. В работе [2] подчеркивается, что существует множество отдельных экологических, экономических и социальных показателей, а также различные подходы зарубежных и отечественных исследователей к разработке показателей. Вместе с тем измерение, обработка, интерпретация и передача информации обходятся дорого, поэтому выбор подходов и показателей ее измерения должен быть адаптирован к конкретным потребностям и условиям конкретной страны ${ }^{2}[3]$.

Целью настоящей статьи является определение сути концепции DPSIR, выявление ее роли в структурировании различных методологических подходов и показателей измерения эколого-экономической информации с единой точки зрения, анализе эколого-экономических взаимодействий на региональном и локальном уровне.

\section{2. Концептуальная модель DPSIR}

В истории подходов к измерению экологической информации были приняты различные схемы ее сбора и обработки, такие как схема PSR (Давление - Coстояние - Реакция), принятая организацией экономического сотрудничества и развития ${ }^{3}$, схема DSR (Движущие силы - Состояние - Реакция), разработанная Комиссией $\mathrm{OOH}$ по устойчивому развитию ${ }^{4}$, а также структура DPSIR (Движущие силы - Давление - Состояние - Воздействие - Реакция), которая была

for Action, report prepared for the G7 Environment Ministers' Meeting, 5-6 May 2019; OECD (2020), Environment at a Glance 2020, OECD Publishing, Paris. URL: https://doi.org/10.1787/4ea7d35f-en

${ }^{2} \mathrm{EaP}$ Green Оценка зеленой трансформации экономики [Электронный ресурс]: руководство для стран восточного партнерства ЕC. Париж, 2016. URL: http://www.greeneconomies-eap.org/ru/resources/EaP\%20GREEN_GGI\%20Guide_clean_RUS_Final.pdf

${ }_{4}^{3}$ Environmental Indicators: OECD Core Set, 1995.

${ }^{4}$ Indicators of Sustainable Development: Framework and Methodology. N.Y.: United Nations, 1996. 
предложена Европейским агентством по окружающей среде [4] и принята многими национальными и европейскими институтами.

Разработка структуры DPSIR является методом систематизации информации и установления причинно-следственных связей между движущими силами, давлением, состояниями и реакциями общества [5]. Эта гибкая структура широко используется для соотнесения человеческой деятельности с состоянием окружающей среды и решения возникающих проблем (рис. 1). Исходным в этой схеме является определение «драйверов» (движущих сил) экономического развития. Движущие силы отражают необходимость деятельности, например, частных лиц и отраслей, являются основными причинами, которые приводят к нагрузке на окружающую среду. Примерами являются потребности людей в сельскохозяйственных землях, энергетике, промышленности, транспорте и жилье. Они ведут к человеческой деятельности, которая вызывает «давление» на окружающую среду, например, к эксплуатации ресурсов и выбросам загрязняющих веществ. В результате давления «состояние» окружающей среды изменяется. Это относится к качеству различных сред окружающей среды (воздух, почва, вода и т. д.) и их последующей способности поддерживать предъявляемые к ним требования (стандарты качества окружающей среды).

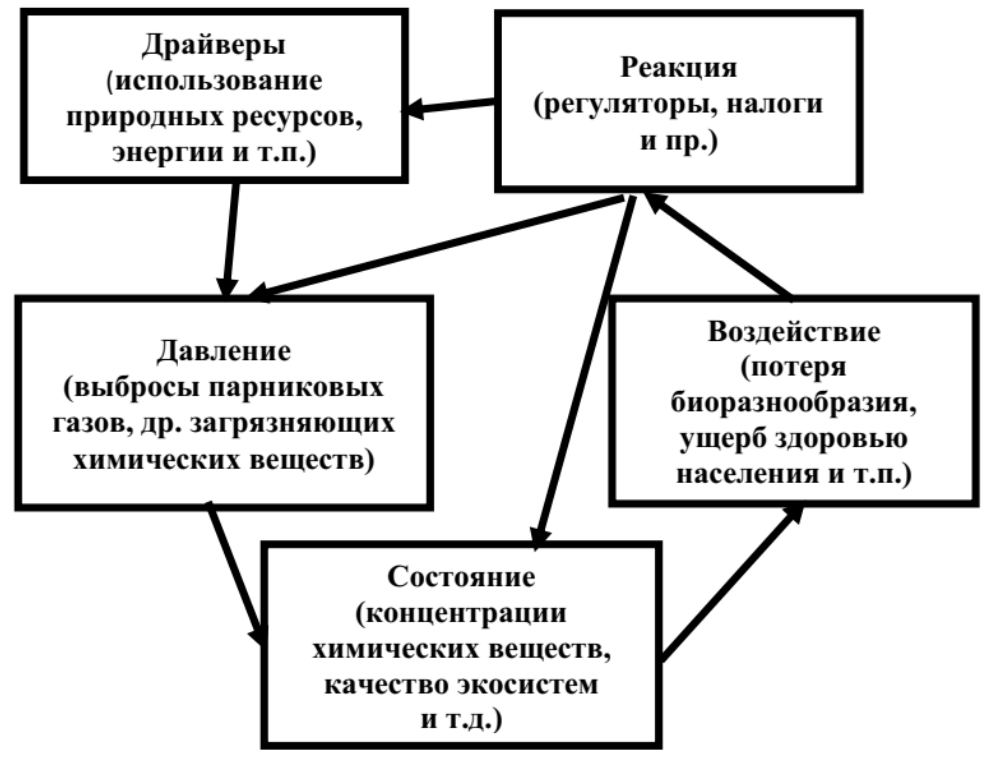

Pис. 1. Структура DPSIR, адаптированная из [5]

Изменения в состоянии могут вызвать «воздействие» на окружающую среду, оказать влияние на здоровье человека, экосистемы, биоразнообразие, стоимость услуг, финансовую ценность и т. д. Воздействие может быть выражено в терминах экологического ущерба. Ответы демонстрируют усилия общества для решения проблем, выявленных в результате оцениваемого воздействия, например, меры политики и планирование действий. Первоначально разработанная для 
T. Б. Бардаханова, В. Д. Мункуева. Использование DPSIR для сравнения методологических подходов к измерению эколого-экономической информации

простого структурирования и информирования о проблемах окружающей среды и для классификации показателей для отчетности концепция DPSIR превратилась в инструмент для анализа воздействий на экологию и дальнейшего принятия решений посредством потоков данных и информации, полученных в результате анализа воздействия [4].

B рамках DPSIR задача лиц, принимающих решения (ЛПР), заключается в анализе территориальной системы и оценке действующих движущих сил, их давления, последствий для переменных состояния и их окончательного воздействия, то есть их негативных внешних эффектов, если таковые имеются. На основе оценки воздействий они должны определить соответствующие ответные меры, чтобы направить конечный эффект, например, на снижение экологического ущерба. Таким образом, в контексте принятия решений, связанных с управлением природными ресурсами, «Воздействия» описывают существующие проблемы, возникающие в результате изменения, обнаруженного в переменных состояния, которое снижает ценность (в количественном, экономическом или качественном отношении) природного ресурса. Подход DPSIR может быть использован на различных уровнях управления - от национальных и международных до местного уровня - в зависимости от имеющихся полномочий. На местном уровне управленцы не могут воздействовать на основные социальноэкономические движущие силы, но могут эффективно решать проблемы состояния окружающей среды или некоторых факторов давления. И наоборот, управленцы более высокого уровня действуют в соответствии с движущими силами и факторами давления, но имеют меньше возможностей заниматься экологическими условиями или факторами состояния. Таким образом, DPSIR может быть использован для принятия решений в области управления природными ресурсами.

Тем не менее методология эффективной реализации процесса принятия решений в рамках DPSIR далеко не совершенна. Изначально исследование по схеме DPSIR представляло собой линейную «цепочку нарушений», которые касаются только социально-экономических факторов. В работе [6] отмечалось, что DPSIR не рассматривает множественные измерения причинности, присущие сложным экологическим и социально-экономическим системам. Несмотря на широкое использование структуры DPSIR, справочный документ с подробным теоретическим и методологическим изложением такого подхода отсутствует. Этот факт способствует различным интерпретациям, как, например, непоследовательное отнесение одних и тех же показателей к пяти компонентам DPSIR [7].

\section{3. Результаты и обсуждение}

3.1 Сравнительный анализ подходов к оценке экологической устойчивости с применением DPSIR

В работе [1] рассмотрены подходы к оценке экологической устойчивости: оценка жизненного цикла (LCA — Life Cycle Assessment), метод планетарных границ (РВ - Planetary Boundary Framework) и цели устойчивого развития (SDGs - Sustainable Development Goals). В таблице 1 дано распределение соответствующих показателей по категориям DPSIR. 
Таблица 1

Количественное распределение показателей по категориям DPSIR в рамках LCA, PB и SDGs

\begin{tabular}{|c|c|c|c|c|c|}
\hline Подходы & Драйверы & Давление & Состояние & Воздействие & Реакция \\
\hline $\begin{array}{l}\text { РВ - касается воздей- } \\
\text { ствия на природную } \\
\text { среду и не предназна- } \\
\text { чен для отражения воз- } \\
\text { действия на здоровье } \\
\text { человека, обеспечивает } \\
\text { способ оценки воздей- } \\
\text { ствия на ОС в абсолют- } \\
\text { ном масштабе, прини- } \\
\text { мая всю Землю в каче- } \\
\text { стве границы системы }\end{array}$ & - & 2 & 6 & 9 & - \\
\hline $\begin{array}{l}\text { LCA - определяет коли- } \\
\text { чество выбросов на всех } \\
\text { этапах жизненного цик- } \\
\text { ла продукта и оценивает } \\
\text { их воздействие. Выяв- } \\
\text { лено } 13 \text { причинно- } \\
\text { следственных цепо- } \\
\text { чек - от выбросов до } \\
\text { ущерба (природная } \\
\text { среда, здоровье челове- } \\
\text { ка и природные ресур- } \\
\text { сы). Оценка по показа- } \\
\text { телям средней точки } \\
\text { или конечной точки }\end{array}$ & - & 1 & 11 & 3 & - \\
\hline $\begin{array}{l}\text { SDGs - } 17 \text { целей, под- } \\
\text { держиваемых } 169 \text { це- } \\
\text { лями, были установлены } \\
\text { в цУР, которые будут } \\
\text { достигнуты к } 2030 \text { г. }\end{array}$ & 6 & 6 & 19 & 16 & 8 \\
\hline
\end{tabular}

Источник: составлено авторами на основе [1]

Индикаторы «Драйверы», «Давление» и «Реакция» легче поддаются регулированию, но их экологическая значимость более косвенная. Тогда как индикаторы состояния и воздействия являются более объективными и надежными в том смысле, что они отражают влияние на состояние окружающей среды. Это объясняет, почему планетарные границы устанавливаются в основном с помощью индикаторов состояний, а в рамках LCA сравниваются экологические показатели состояния и уровень воздействия. В отличие от этого ЦУР нацелены на обеспечение руководящих принципов для нормативных актов, и они должны включать в себя столько индикаторов движущей силы и реагирования, сколько необходимо для достижения очень широкой цели. Существует несколько категорий, в ко- 
T. Б. Бардаханова, В. Д. Мункуева. Использование DPSIR для сравнения методологических подходов к измерению эколого-экономической информации

торых есть только показатели ЦУР, а именно: обработка отходов, изменение морской системы, рыбные ресурсы, энергетические ресурсы, а также продовольственные и сельскохозяйственные ресурсы. Авторы акцентируют внимание на том, что недостаточная разработанность причинно-следственных цепочек в категориях «Драйверы», «Давление» затрудняет оценку существующих проблем. Для выбора обоснованных показателей для поддержки принятия решений необходимо понять контекст индикаторов и проблемы, которые должны решаться с их использованием. Традиционно подход к оценке LCA применяется в основном на продуктовых системах. ЦУР будут в основном осуществляться на отраслевом и национальном уровне, в то время как методология РВ применима на региональном и глобальном уровне.

Таким образом, важность концептуальной модели DPSIR заключается в том, что она позволяет структурировать различные методологические подходы и показатели измерения эколого-экономической информации с единой точки зрения.

3.2 Оценка методологического подхода к зеленому измерению экономик приграничных регионов с использованием DPSIR

Для анализа эколого-экономической ситуации и оценки прогресса в развитии зеленой экономики на конкретных локальных территориях (областях, краях, республиках, провинциях) нами предложена методология построения составного индекса на основе набора показателей, характеризующих различные аспекты взаимодействия между экономикой и окружающей средой (рис. 2).

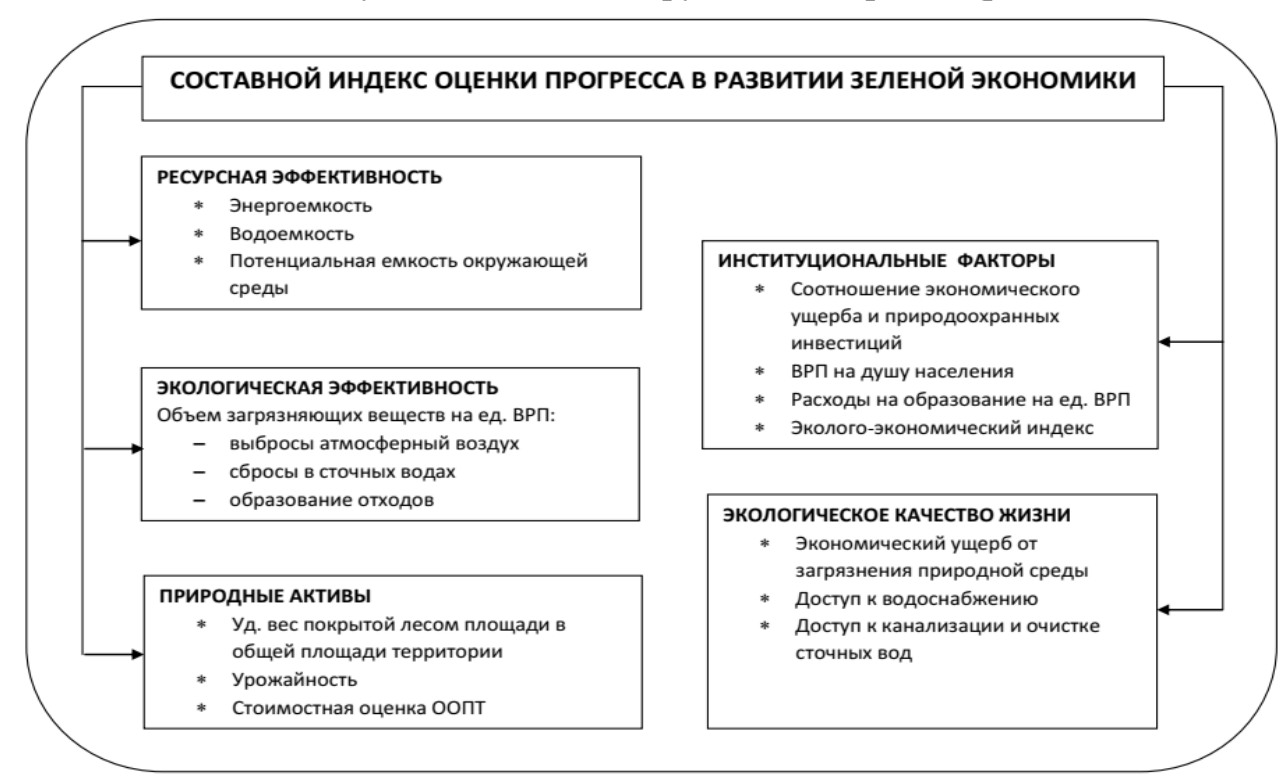

Рис. 2. Направления оценки и показатели для расчета составного индекса для оценки прогресса в развитии зеленой экономики. Источник: разработано авторами на основе ${ }^{5}$

5 OECD (2014), "The OECD green growth measurement framework and indicators", in Green Growth Indicators 2014, OECD Publishing. URL: http://dx.doi.org/10.1787/9789264202030-4-en 
Из рис. 2 видно, что набор показателей для расчета составного индекса состоит из 16 показателей по 5 направлениям оценки. В таблице 2 представлено распределение этих показателей по категориям DPSIR.

Ресурсная эффективность характеризуется показателями и оценкой потенциальной емкости окружающей среды. Энергоемкость и водоемкость являются индикаторами «драйверы», которые приводят к нагрузке на окружающую среду и характеризуют степень эксплуатации природных ресурсов и эффективность использования затрат на единицу продукции, произведенной на основе используемых ресурсов. Потенциальная емкость окружающей среды - это индикатор, характеризующий «воздействие», которое способно выдержать территория, и равный максимальной техногенной нагрузке, которую способна переносить в течение длительного времени совокупность реципиентов и экологических систем территории без нарушения их структурных и функциональных свойств [8-10].

Таблица 2

Распределение показателей составного индекса по оценке прогресса в развитии зеленой экономики по категориям DPSIR

\begin{tabular}{|c|c|c|c|c|c|}
\hline $\begin{array}{c}\text { Направления } \\
\text { оценки } \\
\end{array}$ & Драйверы & Давление & Состояние & $\begin{array}{c}\text { Воздей- } \\
\text { ствие }\end{array}$ & $\begin{array}{c}\text { Ответы } \\
\text { (реакция) }\end{array}$ \\
\hline $\begin{array}{l}\text { Ресурсная } \\
\text { эффективность }\end{array}$ & $\begin{array}{l}\text { Энергоем- } \\
\text { кость } \\
\text { Водоем- } \\
\text { кость }\end{array}$ & - & - & $\begin{array}{l}\text { Потенци- } \\
\text { альная } \\
\text { емкость ОС }\end{array}$ & - \\
\hline $\begin{array}{l}\text { Экологическая } \\
\text { эффективность }\end{array}$ & - & $\begin{array}{l}\text { Экоинтен- } \\
\text { сивность } \\
\text { выбросов, } \\
\text { сбросов и } \\
\text { отходов (3 } \\
\text { показателя) }\end{array}$ & - & - & - \\
\hline $\begin{array}{l}\text { Экологическое } \\
\text { качество жизни }\end{array}$ & - & - & $\begin{array}{l}\text { Доступ к } \\
\text { водоснаб- } \\
\text { жению. } \\
\text { Доступ к } \\
\text { канализации }\end{array}$ & $\begin{array}{l}\text { Экономи- } \\
\text { ческий } \\
\text { ущерб от } \\
\text { загрязне- } \\
\text { ния ОС }\end{array}$ & - \\
\hline $\begin{array}{l}\text { Природные } \\
\text { активы }\end{array}$ & - & - & $\begin{array}{l}\text { Лесопокры- } \\
\text { тая площадь } \\
\text { Урожайность }\end{array}$ & $\begin{array}{l}\text { Стоимост- } \\
\text { ная оценка } \\
\text { оопт }\end{array}$ & - \\
\hline $\begin{array}{l}\text { Институцио- } \\
\text { нальные } \\
\text { факторы } \\
\text { (деятельность } \\
\text { и инструменты } \\
\text { политики) }\end{array}$ & $\begin{array}{l}\text { ВРП на ду- } \\
\text { шу населе- } \\
\text { ния. } \\
\text { Эколого- } \\
\text { экономиче- } \\
\text { ский индекс }\end{array}$ & - & - & - & $\begin{array}{l}\text { ЭУ/Инв. в } \\
\text { охрану ОС } \\
\text { Бюджет- } \\
\text { ные рас- } \\
\text { ходы на } \\
\text { образова- } \\
\text { ние на ед. } \\
\text { ВРП }\end{array}$ \\
\hline
\end{tabular}

Источник: авторская разработка 
T. Б. Бардаханова, В. Д. Мункуева. Использование DPSIR для сравнения методологических подходов к измерению эколого-экономической информации

Показатели приведенных выбросов загрязняющих веществ в атмосферный воздух, сбросов загрязняющих веществ в сточных водах и отходов производства и потребления на единицу ВРП характеризуют интенсивность «давления» антропогенной деятельности на окружающую среду. Эти показатели охватывают те аспекты производства, которым экономические модели и системы учета редко дают количественную оценку. Экологическое качество жизни характеризуется двумя показателями «состояния» - доступом населения к водоснабжению, к канализации и очистке сточных вод. Показатель экономического ущерба от загрязнения природной среды, составной частью которого являются дополнительные затраты и потери вследствие повышения заболеваемости населения и уменьшения продолжительности его жизни из-за ухудшения качества природной среды, также характеризует качество жизни, но в большей степени с точки зрения «воздействия» на него производства [11-12].

База природных активов характеризуется следующими показателями состояния, уменьшение которых ставит будущий рост под угрозу: это показатель покрытой лесом площади в общей площади территории, урожайность сельскохозяйственных культур. Третий показатель природных активов, по нашему мнению, характеризующий стоимостную оценку особо охраняемых природных территорий (ООПТ), которая определяется через недополученный объем ВРП из-за изъятия территории из хозяйственного оборота, в большей степени относится к драйверам, которые снижают нагрузку на окружающую среду. В группу институциональных факторов включено 4 показателя, помогающих оценить эффективность политики, направленной на обеспечение баланса в использовании и сохранении ресурсов окружающей среды. Сопоставление величины экономического ущерба от загрязнения окружающей среды с объемом инвестиций в охрану природы, направленных на предотвращение или ликвидацию негативного воздействия, дает представление о действенности существующего экономического механизма природопользования. Но два показателя (душевой ВРП и экологоэкономический индекс) отражают в первую очередь особенности структуры экономики в том или ином регионе и в большей степени относятся к «драйверам». Так, эколого-экономический индекс позволяет оценить влияние объемов добывающей промышленности на размерность валового регионального продукта (ВРП), уровень загрязнения окружающей среды и степень деградации экологических систем, определить усиление или ослабление экологичности траектории развития регионов, выявить структуру формирования скорректированных чистых накоплений [13].

\section{5. Выводы}

Проведенное исследование позволяет сделать следующие выводы:

1. DPSIR является методом систематизации информации и установления причинно-следственных связей между движущими силами, давлением, состояниями и реакциями общества.

2. Подход DPSIR может быть использован на различных уровнях управления - от национальных и международных до местного уровня - в зависимости от имеющихся полномочий. 
3. Важность концептуальной модели DPSIR заключается в том, что она позволяет структурировать различные методологические подходы и показатели измерения эколого-экономической информации с единой точки зрения.

4. Использование DPSIR в анализе эколого-экономических взаимодействий позволяет выявить узкие места и оценить правильность установления причинноследственных цепочек, способствует выбору правильных наборов индикаторов для конкретной цели.

5. Разработанный на основе 16 показателей составной индекс по оценке прогресса в развитии зеленой экономики практически отражает все категории DPSIR и позволяет отразить разные аспекты эколого-экономического развития на региональном и локальном уровне.

Несомненно, что в рассмотренных методологических подходах к измерению эколого-экономической информации многие показатели не учтены из-за сложностей расчетов или ограничений в доступе к данным, другие находятся в стадии разработки. Необходимы дополнительные исследования для установления причинно-следственных цепочек и обеспечения надлежащих показателей в будущем.

Статья подготовлена в рамках выполнения государственного задания Байкальского института природопользования Сибирского отделения Российской академии наук (БИП CO PAH).

\section{Литература}

1. Dong Y., \& Hauschild M. Z. Indicators for environmental sustainability // Procedia C I R P. 2017. № 61. C. 697-702.

2. Бардаханова Т. Б., Ерёмко 3. С. Сравнительный анализ развития «зеленой» экономики в приграничных регионах экономического коридора Шелкового пути [Электронный ресурс] // Региональная экономика: теория и практика. 2020. Т. 18, вып. 3. С. 592606. URL: https://doi.org/10.24891/re.18.3.592 (дата обращения: 20.08.20).

3. Hsu A. et al. Environmental Performance Index // New Haven, CT: Yale University, 2016. 200 p. URL: www.epi.yale.edu (дата обращения: 20.08.20).

4. Smeets E., Weterings R. Environmental Indicators: Typology and Overview // Technical Report No. 25; European Environment Agency: Copenhagen, Denmark, 1999. P. 19.

5. Ness B., Anderberg S., Olsson L. Structuring problems in sustainability science: The multi-level DPSIR framework // Geoforum. 2010. № 41. P. 479-488.

6. Maxim L., Spangenberg J. H., O'Connor M. An analysis of risks for biodiversity under the DPSIR framework // Ecol. Econ. 2009. № 69. P. 12-23.

7. Giupponi C. From the DPSIR reporting framework to a system for a dynamic and integrated decision making process // MULINO Conference on "European policy and tools for sustainable water management" 21-23 November, 2014, Venice (Italy). 210 p. URL: https://www.researchgate.net/publication/229047372 (дата обращения: 20.08.20).

8. Акимова Т. А., Хаскин В. В. Основы экоразвития. М.: Изд-во Рос. экон. акад., 1994. $312 \mathrm{c}$.

9. Батомункуев В. С., Аюшеева С. Н. Сравнительная оценка природного потенциала самоочищения и антропогенных воздействий в трансграничном речном бассейне p. Селенги // Вестник БГУ. Экономика и менеджмент. 2015. Вып. 4. С. 43-49.

10. Бардаханова Т. Б., Ерёмко 3. С., Аюшеева С. Н. Концепция разработки информационной базы показателей потенциальной емкости окружающей среды [Электронный 
T. Б. Бардаханова, В. Д. Мункуева. Использование DPSIR для сравнения методологических подходов к измерению эколого-экономической информации

ресурс] // Региональная экономика: теория и практика. 2018. Т. 16, № 9. С. 1766-1776. URL: https://doi.org/10.24891/re.16.9.1766 (дата обращения: 20.08.2020).

11. Михеева А. С., Аюшеева С. Н. Сравнительный анализ экономического ущерба окружающей среде на модельных территориях // Вестник ВСГУТУ. 2014. № 3(48). С. 9297.

12. Эколого-экономический индекс регионов РФ. Методика и показатели для расчета / С. Н. Бобылев [и др.]. М., 2012. 152 с.

\section{APPLYING DPSIR TO COMPARE METHODOLOGICAL APPROACHES TO MEASUREMENT OF ENVIRONMENTAL AND ECONOMIC INFORMATION}

\section{Taisiya B. Bardakhanova}

Dr. Sci. (Econ.), Leading Researcher

E-mail: tbard@binm.ru

\section{Viktoria D. Munkueva}

Leading Engineer

E-mail: munvic@mail.ru

Baikal Institute of Nature Management SB RAS

8 Sakhyanovoy St., Ulan-Ude 670047, Russia

Ecological and economic information is an important tool for describing causal relationships between ecological, economic, social, and technological environments. We propose to use DPSIR as a conceptual model for structuring different approaches and indicators in one point perspective. The article provides a comparative analysis of approaches to assessment of environmental sustainability using DPSIR: life cycle assessment (LCA), planetary boundaries method (PB) and sustainable development goals (SDGs). Application of DPSIR for the analysis of environmental and economic interactions allows identifying weak points and assessing the correctness of causal chains, provides the selection of proper sets of indicators for a specific goal. The composite index for assessing progress in the development of a green economy worked out by us on the basis of 16 indicators reflects almost all DPSIR categories and different aspects of environmental and economic development at the regional and local levels.

Keywords: ecological and economic information; indicators; DPSIR; green economy; composite index. 